\title{
Two state disputes and outside intervention: The case of Nagorno-Karabakh conflict.
}

\author{
Ani Harutyunyan*
}

February 8, 2017

\begin{abstract}
The paper proposes a game theoretical model of a dispute between two states. It analyzes the possible outcome of the dispute and the probability of war depending on the distribution of power between those states, the costs of fighting in the war and the level of uncertainty about each other's costs. The paper also examines two types of outside intervention analyzing their separate and joint effect on the final outcome and the probability of war. The model is applied to the case of Nagorno-Karabakh conflict and some concluding remarks are provided regarding the probability of war break out and possible resolutions of the conflict.
\end{abstract}

Keywords: interstate conflict; third party intervention; coercive intervention; Nagorno-Karabakh; Armenia; Azerbaijan

JEL Classification: F50, F51, F52, N40, N44, N45

${ }^{*}$ LICOS - Centre for Institutions and Economic Performance, KU Leuven, Belgium. Email: ani.harutyunyan@kuleuven.be. The author would like to thank Zaier Aoani, Avner Shaked and Martijn Huysmans, as well as seminar participants at the International School of Economics in Tbilisi (ISET) and University of Zürich. 


\section{Contents}

1 Introduction 3

2 The Model 6

2.1 Perfect information . . . . . . . . . . . . . . . . . . 7

2.2 Imperfect information . . . . . . . . . . . . . . . . 9

3 Comparative Statics $\quad 10$

3.1 The effect of a change in the level of uncertainty . . . . . . . . . . . . 11

3.2 The effect of a change in Challenger's costs for war . . . . . . . . . . 12

3.3 The effect of a change in the balance of power . . . . . . . . . . . 12

4 Outside intervention $\quad 13$

4.1 Intervention that targets Defender's costs . . . . . . . . . . . . . . 13

4.2 Intervention that changes the balance of power in favor of Defender . 16

4.3 The joint effect of a two-sided intervention . . . . . . . . . . . . 20

5 Conclusion $\quad 23$

$\begin{array}{lr}\text { A Appendix } & 26\end{array}$

A.1 Proof of Proposition 2 . . . . . . . . . . . . . . . . . 26

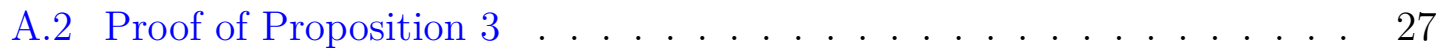

A.3 Proof of Proposition $4 \ldots \ldots \ldots$. . . . . . . . . . . . 27

A.4 Proof of Proposition $5 \ldots \ldots \ldots \ldots \ldots$

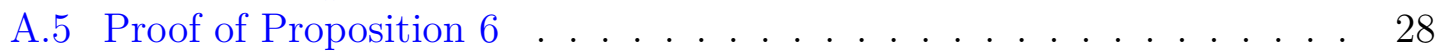

A.6 Proof of Proposition 7 . . . . . . . . . . . . . . . . . . . . . . . . 29

A.7 Proof of Proposition $8 \ldots \ldots \ldots \ldots$

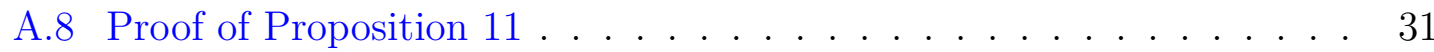




\section{Introduction}

Disputes between two states are common events across the world. If the disputants do not resolve the issue via negotiations, they may go to war. In most cases those two states are not the only participants in the war, there is always a possibility of intervention by other states that pursue their own interests and affect the final outcome.

Consider two states that are involved in a dispute. One side is "dissatisfied" and claims a territory from the other state, while the other is "satisfied" and prefers the status quo to conflict; therefore it may wish to make some concessions to the other side to avoid a possible conflict. This paper models such a dispute between two states in the framework of game theory. Hence, the purpose of this research is limited to game theoretical aspects of the conflict and does not include an examination of its underlying nature or detailed history.

The theory is applied to the case of Nagorno-Karabakh conflict. Nagorno-Karabakh (Artsakh) is a landlocked region in the South Caucasus. It was claimed by both Armenia and Azerbaijan when both countries first became independent in 1918 after the fall of the Ottoman Empire, and a brief war over Nagorno-Karabakh broke out in 1920. The dispute was largely shelved after the Soviet Union established control over the area and created the Nagorno-Karabakh Autonomous Oblast within the Azerbaijan Soviet Republic in 1923. During the fall of the Soviet Union the conflict over the region re-emerged. Although there was no formal declaration of war, there was large-scale combat between Azerbaijan and the Armenian population of NagornoKarabakh in late 1980-s. In 1991 the predominantly Armenian-populated region of Nagorno-Karabakh held a referendum and declared its independence backed by the Republic of Armenia. The large-scale ethnic conflict escalated into a full-scale war between the two newly-independent Republics of Azerbaijan and Armenia. The war ultimately brought victory for the ethnic Armenians who took Nagorno-Karabakh region under their control and additionally pushed on to control territories outside the region, creating a buffer zone and linking Nagorno-Karabakh with Armenia. Since the ceasefire of 1994, representatives of the governments of Armenia, Azerbaijan and unrecognized Nagorno-Karabakh Republic have been involved in peace talks mediated by the OSCE Minsk Group on the region's disputed status. The format of the peace talks has slightly changed by the end of the 1990s, and currently the main actors and sides of this conflict are the Republics of Armenia and Azerbaijan. Azerbaijan is in "dissatisfied" position, since it claims Nagorno-Karabakh as part of its territory, which is under ethnic Armenian control. Armenia is "satisfied" and prefers the current status quo to conflict. 
This paper develops a model capturing the current state of the conflict and makes predictions on its possible future developments. The conflict is modeled based on Fearon (1995)'s take-it-or-leave-it bargaining game. The dissatisfied state makes an offer to the satisfied state demanding a part of its territory. In the case of Nagorno-Karabakh conflict Azerbaijan can demand from Armenia the whole territory of Nagorno-Karabakh region or a part of it, or only the buffer zone surrounding the Nagorno-Karabakh region. ${ }^{1}$ The satisfied state can accept the demand and give up that part of its territory or reject the proposal, in which case the two states go to war. ${ }^{2}$ Note that there is no assumption about which state starts the war. The war is a result of failed negotiations.

Extensive literature has been devoted to the modeling of war. In this study the war is modeled as a costly lottery based on a model proposed by Powell (1996). War is considered a risky event where the outcomes are uncertain. Players have costs for fighting and have expectations about the outcome. These expectations are based on the distribution of power which is common knowledge among players. The assumption about distribution of power being common knowledge is not a strong assumption for the case of Nagorno-Karabakh conflict, given the fact that the main actors of the conflict are small neighbor countries formerly belonging to the same bloc and have already had an experience of war with one another. First, under the assumption of perfect information, it is shown that there is no risk of war and the states always achieve a peaceful solution through negotiations. Next, the assumption is relaxed and uncertainty is introduced into the model.

Following Powell (1996), it is assumed that the parties are not informed about each others costs of war. ${ }^{3}$ Uncertainty makes war possible with positive probability. The probability of war depends on the level of uncertainty, distribution of power, and costs for fighting. Third parties can intervene and alter these factors affecting the probability of war and the final outcome of the dispute.

There are different forms of third party intervention; conciliation, mediation and other forms of conflict management. As a form of third party intervention, this paper examines coercive intervention and considers two ways of implementations. The first

\footnotetext{
${ }^{1}$ The return of the territories surrounding Nagorno-Karabakh to Azerbaijani control has been proposed by the OSCE Minsk Group as a possible condition of settlement.

${ }^{2}$ The current official rhetoric of Azerbaijani government with war threat statements and the attempts in April 2016 to escalate a war clearly demonstrate that Azerbaijan is willing to go to war if Armenia rejects its proposals.

${ }^{3}$ There are several alternative ways of incorporating uncertainty into model. For example, Powell (2004) introduces uncertainty over the distribution of power. Fearon (1995) in its take-it-or-leave-it game represents uncertainty by a function with properties that capture a wide range of probability distributions.
} 
is shifting the balance of power among players, which can be done by using military force and/or providing weapons, money or other forms of aid. The second way is to target one of the player's costs for fighting, for instance by economic sanctions and embargoes. Given the geopolitical situation in the South Caucasus, the conflict between Armenia and Azerbaijan is subject to interventions by third-party countries which seek to promote their own interests in the region by supporting one or the other side.

The Russian Federation has strong interests in the region. Together with several countries, including Armenia, Russia founded the Collective Security Treaty Organization, whose main goals are to deepen military-political cooperation and to create mechanisms for providing assistance, including military assistance to member states which find themselves victims of aggression. Given the existence of this organization, our model considers the possibility of intervention by Russia, which shifts the balance of power in favor of Armenia by providing military assistance.

In order to support its ally Azerbaijan in the Nagorno-Karabakh war, the Republic of Turkey closed its border with Armenia in 1993 imposing an economic embargo on the country. This is a classical example of coercive intervention that increases the costs for fighting of one of the parties. The ongoing blockade isolated Armenia from all the regional pipeline and infrastructure projects; Baku-Tbilisi-Ceyhan oil pipeline, Baku-Tbilisi-Erzurum natural gas pipeline, Kars-Tbilisi-Baku railway, all of which bypass Armenia. The border between Turkey and Armenia remains closed till now. The recent negotiations to open it were unsuccessful. Even if there is a possibility of opening the border, Turkey always has the option of closing it again when a war breaks out, as a way to support Azerbaijan. Taking account of these developments and also the historical and political aspects of Armenian-Turkish relations, the model considers the possibility of an intervention by Turkey that targets Armenia's costs for fighting.

The paper incorporates third parties in the model based on an approach suggested by Rauchhaus (2005), that allows to identify above mentioned two ways of implementation of coercive intervention ${ }^{4}$. Rauchhaus (2005) assumes that the players are risk neutral. This paper takes a more general approach assuming that players can also be risk averse. Given the presumption that state leaders normally wish to retain the territory and power rather than accept gambles that have a risk of eliminating the state and the regime, this approach is much more plausible. Additionally, this paper examines the joint effect of two interventions which happen simultaneously. This investigation is particularly relevant for the case of the Nagorno-Karabakh conflict.

The paper is organized as follows. Section 2 presents the formal model. The first

\footnotetext{
${ }^{4}$ For an alternative approach see Siqueira (2003)
} 
part assumes perfect information, the second part introduces uncertainty. Section 3 presents the results of comparative statics. Section 4 incorporates a third party into the model. The first part of the section incorporates a form of coercive intervention that targets one of the disputant's cost, and the second part incorporates a form of coercive intervention that shifts the balance of power. The last part of the Section 4 allows two forms of intervention to act simultaneously and investigates their joint effect. The final section of the paper, Section 5, makes concluding remarks on the results of the model and discusses its implications on the probability of war break out and possible resolutions of the Nagorno-Karabakh conflict. The Appendix presents the proofs of the propositions and results.

\section{The Model}

There are two states in the model bargaining about revising the territorial status quo. The states are aware of the distribution of power, but the information about their costs for using force is private. In the first part of the section the case of perfect information is discussed, when the costs for fighting are also common knowledge. It is shown that in that case the war is avoidable. The second part of the section, where costs for fighting are private information, a function of probability of war is derived.

Consider two nation-states having preferences over a territory represented by interval $X=[0,1]$. The nation-state controlling the territory is called Defender or Player D. Its objective is to maintain that territory. The other nation-state challenging the status quo and making claims over the territory $X$ is called Challenger or Player C. The game starts with Challenger making a demand for a part of the territory controlled by Defender. The demanded part is denoted by $x$, where $x \in X$. The rest of the territory which is $1-x$ is offered to Defender. If Defender accepts the offer then the parties end up with $x$ and $1-x$ and get utilities $u(x)$ and $u(1-x)$ respectively for Challenger and Defender, where without loss of generality $u(0)$ is set to 0 and $u(1)$ is set to 1 .

The players are assumed to be risk neutral or risk averse, the utility functions are continuous, increasing and weakly concave,

$$
\begin{gathered}
u^{\prime}(x)>0 \\
u^{\prime \prime}(x) \leq 0 .
\end{gathered}
$$

If Player D rejects the offer, the parties go to war. The war is modeled as a costly lottery. It costs $c$ for Player $\mathrm{C}$ and $d$ for Player $\mathrm{D}$, where $c, d \in[0,1]$. The probability that Player $\mathrm{C}$ wins the war is $p \in[0,1]$. The winner has the right to choose $x \in$ 


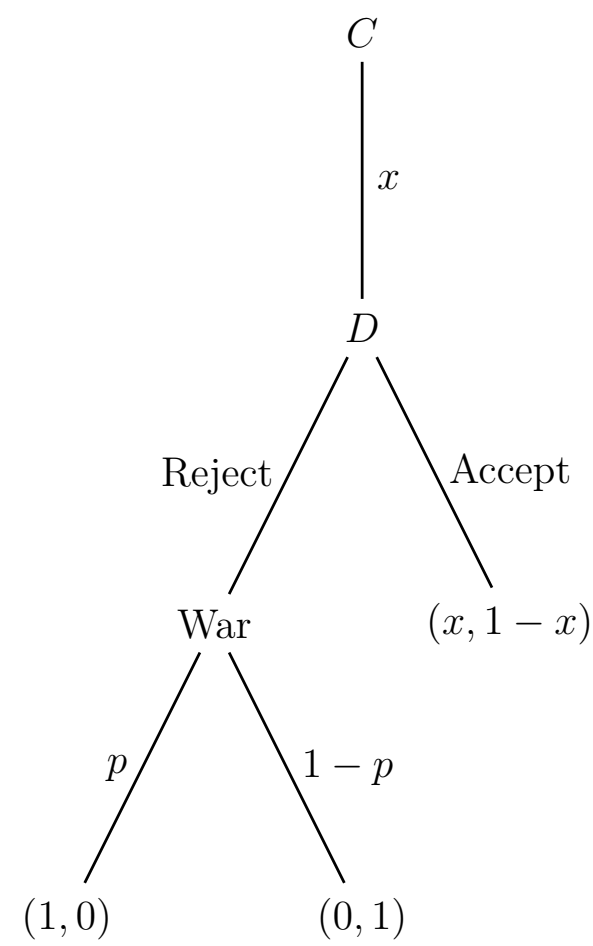

Figure 1: Take it or leave it game.

$X$, which, given the increasing utility functions, is 1. It follows that Challenger's expected payoff from war is:

$$
p \times 1+(1-p) \times 0-c=p-c,
$$

and Defender's expected payoff is:

$$
p \times 0+(1-p) \times 1-d=1-p-d .
$$

\section{$2.1 \quad$ Perfect information}

This subsection of the paper assumes perfect information. Both players are perfectly informed about each other's costs, the distribution of power, utilities for different outcomes, etc. It will be shown that under this assumption there is no risk of war.

The game is graphically represented in Figure 1.

Challenger starts the game by making a proposal of $x$, then Defender has to accept or reject the proposal. When Defender accepts, the game ends and the Challenger 


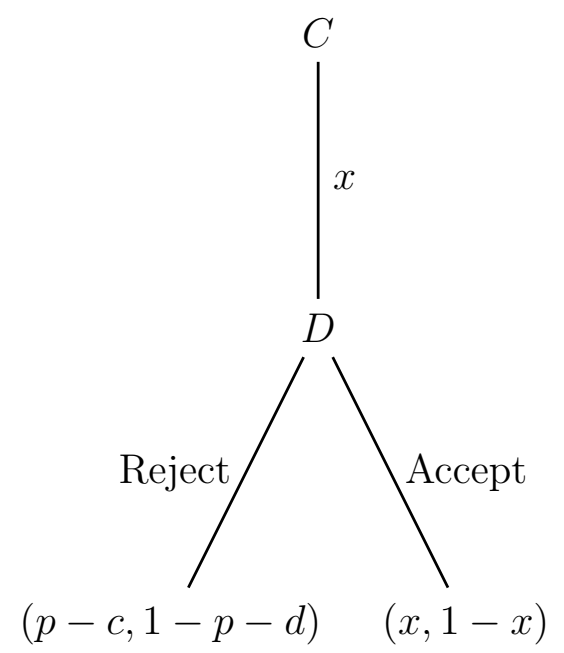

Figure 2: Take or leave it game: First reduction.

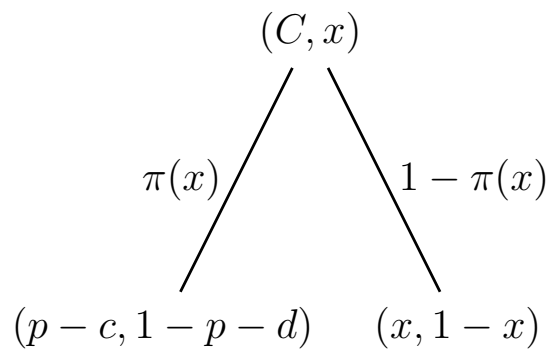

Figure 3: Take or leave it game: Second reduction.

gets its proposal leaving the rest to Defender. When Defender plays the reject option, parties go to war. The probability that Challenger will get 1 is $p$. So Challenger's expected payoff for war is $1 \times p+0 \times(1-p)-c=p-c$ where $c$ is its cost for war. Defender's expected payoff is $1 \times(1-p)+0 \times p-d=1-p-d$. Based on the calculations of the expected payoffs for war, the reduced form of the game is presented in Figure 2.

Using subgame perfection we know that Defender will accept the offer only if its utility (denoted $u_{d}$ ) from that offer is greater than utility from the expected payoff for war. That is, if

$$
u_{d}(1-x) \geq u_{d}(1-p-d) .
$$

When $u_{d}(1-x)=u_{d}(1-p-d)$, the player is indifferent between accepting the offer or 
going to war. Because of the assumption of non-decreasing utility functions the offer will be accepted only when $1-x \geq 1-p-d$. Knowing Defender's expected utility for war, Challenger can propose such $x$ that is acceptable for Defender and does not lead to war. Because Challenger's utility function (denoted $u_{c}$ ) is nondecreasing function, it will propose the highest $x$ which is acceptable for Defender; that is $x=p+d$. At the same time Challenger realizes that it makes sense to make a proposal acceptable for Defender, if there is such $x$ that provides utility higher than the utility from expected payoff for war;

$$
u_{c}(x) \geq u_{c}(p-c) \text {. }
$$

So, Challenger will make proposal of $x \geq p-c$. It means that there is such $x$ that provides utility higher than the utility from expected payoff for war if $p-c \leq 1$, but it is always the case, as both $p$ and $c$ are from $[0,1]$ interval.

The other question is whether the proposal of $x \geq p-c$ is acceptable for Defender. It is acceptable only if $x \leq p+d$. Noting that $p-c \leq p+d$, we can conclude that there is always such $x$ that will be offered by Challenger and acceptable for Defender. This leads to the following result;

Proposition 1 When the disputants are perfectly informed about each other, there is no risk of war.

This Proposition suggests that the disclosure of information about disputants may lead to peaceful resolutions.

\subsection{Imperfect information}

Here it is assumed that the information about players' costs is private and Player $\mathrm{C}$ does not know Player D's costs for war while proposing an offer.

Assume Player D's costs for war are uniformly distributed with probability density function of $f(d)=\frac{1}{2 e}$ for $\mu-e \leq d \leq \mu+e$.

Thus, the average cost of Player D is $\mu$, and $e$ captures the level of uncertainty. The higher the $e$, the higher the uncertainty about Defender's costs. Note that since $d \in[0,1]$, it is reasonable to assume that $e<1 / 2$.

Now, when making an offer, Challenger does not know the exact $d$ to be able to propose the marginal demand acceptable for Defender. When Challenger's proposal is greater than $p+d$, the offer will be rejected by Defender and parties will go to war. Therefore, the probability that $x>d+p$ is called the probability of war. Let's 
denote it by $\pi$. Then,

$\pi(x)=\operatorname{Prob}(x>d+p)=\operatorname{Prob}(d<x-p)=\operatorname{Prob}(d \in[\mu-e, x-p))=\int_{\mu-e}^{x-p} \frac{d d}{2 e}=\frac{x-p-\mu+e}{2 e}$.

The probability of war is an increasing function on the demand of Challenger. This is an intuitive result, since the higher the proportion Challenger wants to get from Defender the higher the probability that Defender will prefer fighting rather than accepting that high demand. Therefore when proposing $x$, Challenger faces a tradeoff. A high proposal increases the probability of getting rejection from Defender and ending up with post-war payoffs. By proposing low $x$, Challenger loses the opportunity of getting more from Defender, whose costs for fighting might be high. Challenger's expected utility is:

$$
U_{c}(x)=\pi(x) u(p-c)+(1-\pi(x)) u(x)
$$

which can be written as follows:

$$
U_{c}(x)=u(p-c)+(1-\pi(x))(u(x)-u(p-c)) .
$$

The optimal offer of Player $\mathrm{C}$ that maximizes its expected payoff is denoted by $x^{*}$. At that point the differential of the expected utility with respect to $x$ should be equal to zero.

$$
\frac{\partial \pi}{\partial x}\left(x^{*}\right)\left(u\left(x^{*}\right)-u(p-c)\right)=\left(1-\pi\left(x^{*}\right)\right) u^{\prime}\left(x^{*}\right) .
$$

We note that the RHS of equation (2) is nonnegative. Since

$$
\frac{\partial \pi}{\partial x}\left(x^{*}\right)=\frac{1}{2 e} \geq 0
$$

it follows that

$$
u\left(x^{*}\right)-u(p-c) \geq 0 .
$$

As the function $u$ is non-decreasing, we have $x^{*} \geq p-c$. This is the range from where Player $\mathrm{C}$ makes its proposal.

\section{Comparative Statics}

The size of the optimal demand and the magnitude of the probability of war depends on the following parameters: the level of uncertainty, distribution of power, and the costs for fighting. Changes in these parameters will lead to change in the size of the optimal demand and the probability of war. 


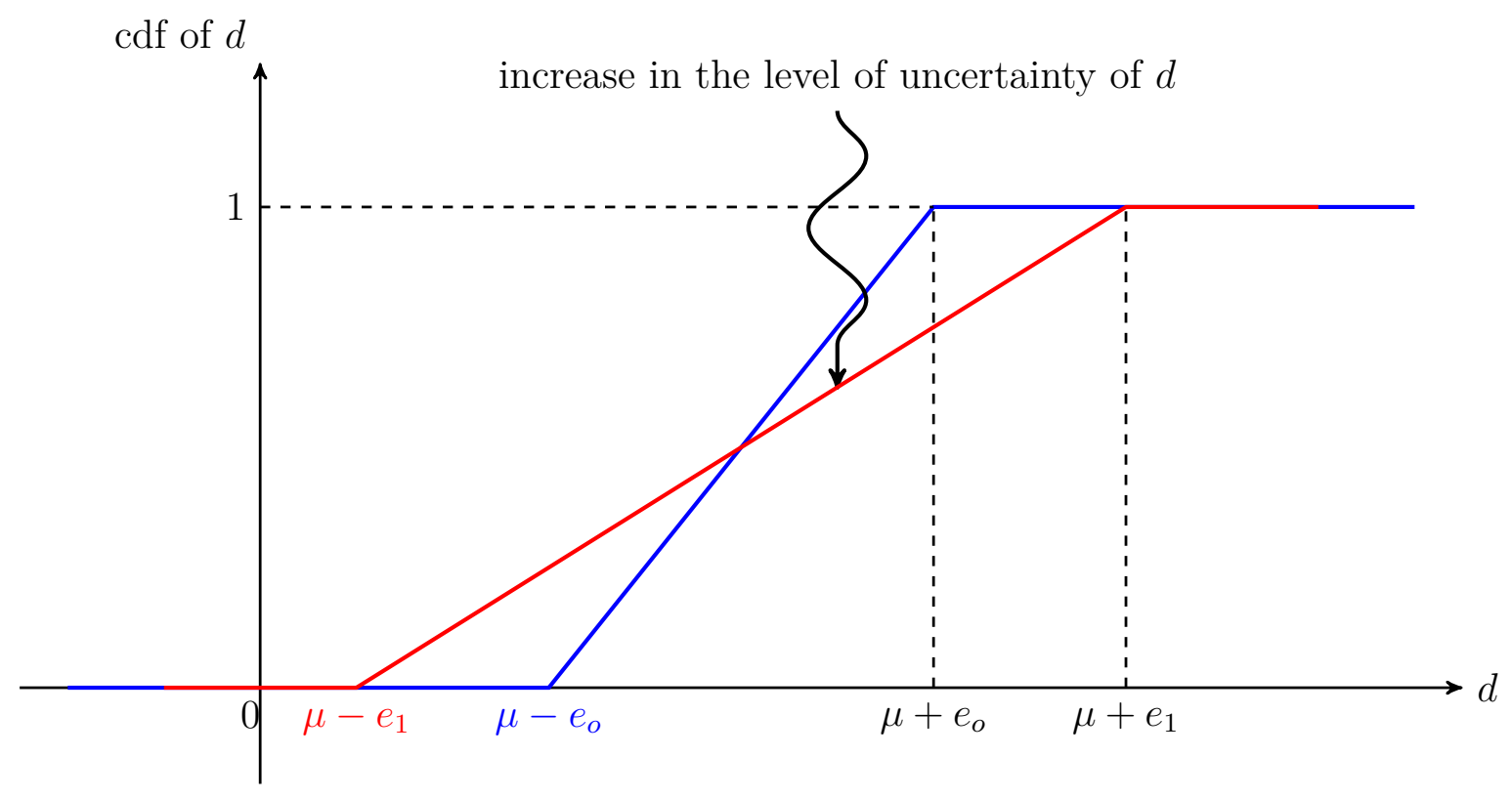

Figure 4: A mean preserving increase in the level of uncertainty $d$.

\subsection{The effect of a change in the level of uncertainty}

The level of uncertainty, which is measured by $e$, shows how uncertain Challenger is about Defender's costs. Figure 4 represents two cumulative distribution functions of Defender's cost for war with the same mean $\mu$ and different errors $\left(e_{1}>e_{0}\right)$. The higher the $e$, the more uncertain Challenger is about Defender's cost. This section investigates the effect of the level of uncertainty on Challenger's optimal demand and probability of war.

Proposition 2 An increase in the level of uncertainty increases Challenger's optimal demand.

Uncertainty makes Challenger to take more assertive role in the bargaining process. Proposition 2 also implies that Player D has incentives to send true signals about its cost in order secure lower demand from Player C.

Proposition 3 shows how the change in the level of uncertainty effects the probability of war.

Proposition 3 If the probability of war is smaller than $1 / 2$, then an increase in the level of uncertainty increases the probability of war. 
This result is intuitive. When there is no uncertainty, there is no chance of war; the probability of war is zero. Small increases in the level of uncertainty leads to increase in the probability of war from zero to $1 / 2$. After it reaches $1 / 2$, the effect of uncertainty level on the probability of war is ambiguous.

Remark 1 If the probability of war is higher than $1 / 2$, the effect of the level of uncertainty on the probability of war is ambiguous.

Note that when players are risk neutral, an increase in the level of risk increases the probability of war unambiguously. In that case a disclosure of information about costs for war reduces the probability of war unambiguously.

\subsection{The effect of a change in Challenger's costs for war}

It is assumed that Challenger knows how much it costs to go to war, and its willingness to go to war depends on that cost which is the price of war. So, the demand it will make from Defender directly depends on that cost.

Proposition 4 The higher Challenger's costs for war, the lower its demand from Defender, and the lower the probability of war is.

When the costs for war are high for the Challenger, it would like to avoid it by decreasing its demand from Defender, which in turn increases the probability that the offer will be accepted. As result the probability of war decreases.

This proposition implies that a weak Challenger is not willing to dispute the status-quo much and the stronger Challenger becomes, the higher the probability that there will be a war.

\subsection{The effect of a change in the balance of power}

The balance of power is determined by $p$ which is the probability that Challenger wins the war. The probability that Defender wins the war is $1-p$. When Challenger makes a decision about the proposal, it takes into account the probability of winning the war, so the size of that probability directly effects the size of the proposal.

Proposition 5 The higher the probability that Challenger wins the war, the higher the offer proposed by Challenger. 
The higher the probability that Challenger wins the war, the lower its opportunity cost for war. Therefore Challenger will not avoid the war and will make a high demand from Defender, since it knows that in the case of war the probability of getting everything is high. Defender is also aware of that that, but the question is how it effects its willingness to accept that demand.

Proposition 6 If the optimal demand proposed by Challenger is high enough (here that means $\left.x^{*} \geq p+\frac{\mu+e-c}{2}\right)$, then a change in the balance of power, that favors Player $C$, increases the probability of war.

A unit change in Challenger's probability of winning increases the optimal demand with more than one unit when that optimal demand is already high enough. This unambiguously leads to increase in the probability of war, since the Defender by getting higher demand compared with the small shift in the balance of power is likely to reject the proposal and go to war.

\section{Outside intervention}

This section discusses two type of interventions. One that targets Defender's costs and another that shifts the balance of power in favor of Defender. The effect of these interventions will be discussed first separately, then jointly.

In the case of Nagorno-Karabakh conflict this investigation aims to reveal the effect of possible intervention of Turkey (Player $\mathrm{T}$ in the model) and Russia (Player $\mathrm{R}$ in the model) on the probability of war and the final outcome from the resolution of the conflict.

\subsection{Intervention that targets Defender's costs}

This subsection discusses an intervention from a third party (Player T), that targets Player D's costs for war by increasing it from $d$ to $d+\delta$, where $\delta \geq 0$. The game is represented in Figure 5.

Player C proposes $x$. When Player D accepts the offer, it gives $x$ to Player $\mathrm{C}$ and ends up with $1-x$. If the offer is rejected, both parties go to war and it is Player T's turn to play. Player T has two possible actions: to intervene by targeting Player D's costs or not to intervene at all. The strategy that Player $\mathrm{T}$ will follow depends on its net utility from intervention. We assume that Player $\mathrm{T}$ gets utility of 0 if it chooses not to intervene and gets utility of $U_{T} \in[0,1]$ if it intervenes. However intervention 


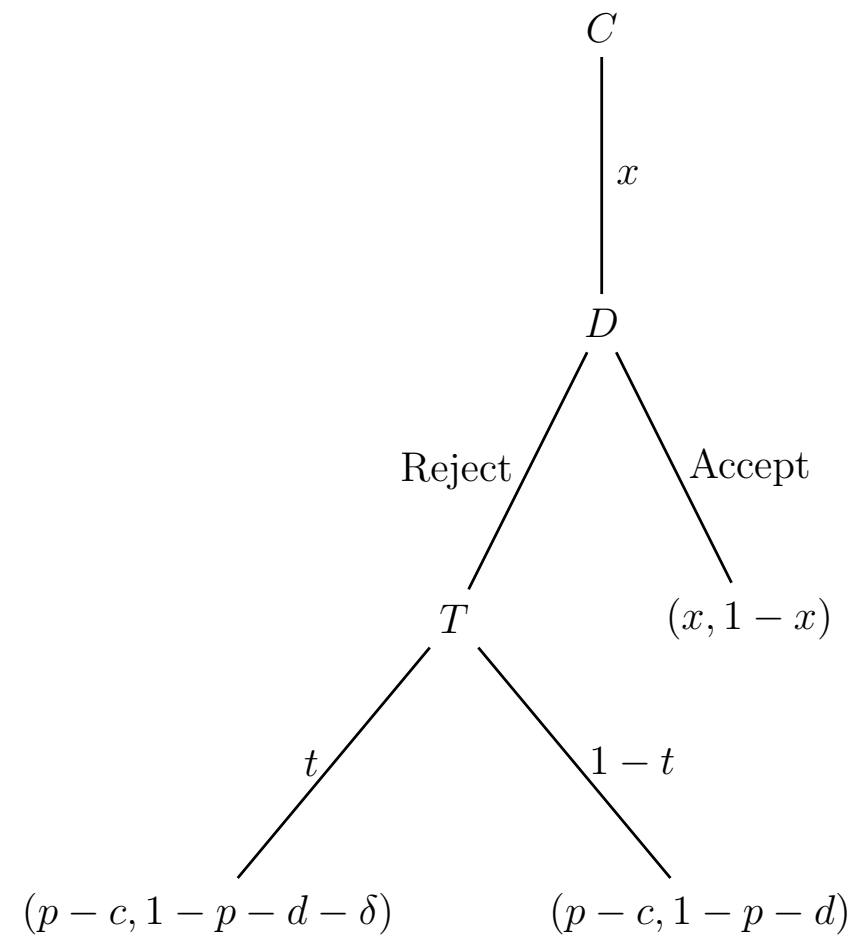

Figure 5: Intervention that targets Player D's costs. 
is costly and the cost is $C_{T} \in[0,1]$, so the net utility from intervention is $U_{T}-C_{T}$. The Player $\mathrm{T}$ will choose to intervene if $U_{T}-C_{T} \geq 0$.

Assume that the two parties, $C$ and $D$, know the costs that Player T incurs due to an intervention, but they are not informed about the level of utility that it gets from the intervention.

Assume the utility Player $\mathrm{T}$ gets from intervention is uniformly distributed in $[0,1]$, and the cost of intervention that is common knowledge among players is $C_{T}=$ $1-t$, where $t \in[0,1]$.

The probability that Player $\mathrm{T}$ does not intervene is $\operatorname{Prob}\left(U_{T}-C_{T} \leq 0\right)=$ $\operatorname{Prob}\left(U_{T} \leq 1-t\right)=1-t$. And the probability of intervention is $\operatorname{Prob}\left(U_{T}-C_{T} \geq\right.$ $0)=\operatorname{Prob}\left(U_{T} \geq 1-t\right)=t$.

Players do not know the net utility that Player $\mathrm{T}$ gets from intervention, thus, they do not know whether there will be an intervention or not. However, based on information on the distribution of utility function, they can distinguish two types of players. First type is the one whose utility is greater than costs of intervention and it does intervene, a motivated Player T. The second type, an unmotivated Player T, gets negative net utility from intervention and it chooses not to intervene in case of war. Two main parties play with these two types of outside players. The probability that they will face a motivated player is $t$ and the probability that they will face an unmotivated player is $1-t$. Player C's expected payoff of war when there is a chance of intervention by third party $\mathrm{T}$ is:

$$
t(p-c)+(1-t)(p-c)=p-c
$$

Note that the expected payoff for war is unchanged for Player C, as it secures the same outcome in the war no matter Player $\mathrm{T}$ intervenes or not, because Player $\mathrm{T}$ targets only Player D's costs.

Player D's expected payoff:

$$
t(1-p-d-\delta)+(1-t)(1-p-d)=1-p-d-t \delta .
$$

Knowing this, the Player $\mathrm{C}$ will propose such $x$ that $1-x \geq 1-p-d-t \delta$.

Here the assumption of incomplete information is maintained about the Players costs for war. Player $\mathrm{C}$ does not know the exact cost that Player D incurs in war, but knows that it is uniformly distributed in $[\mu-e, \mu+e]$. The information on probability of Player T's intervention shifts this interval to $[\mu+t \delta-e, \mu+t \delta+e]$. Player D's costs for war become uniformly distributed in $[\mu-t \delta, \mu+t \delta]$.

In this case the probability of war is:

$$
\pi(x)=\operatorname{Prob}(1-x<1-p-d-t \delta)=\operatorname{Prob}(d<x-t \delta-p)=\frac{x-p-\mu-t \delta+e}{2 e} .
$$


Taking into account the probability of war, Player $\mathrm{C}$ makes a proposal that maximizes its expected utility.

$$
U(x)=(1-\pi(x)) u(x)+\pi(x) u(p-c) .
$$

Proposition 7 When there is a chance of a third party intervention that targets Player D's costs, Player C's optimal demand increases compared to when there is no chance of intervention.

Player T by increasing Player D's costs makes the war a more expensive alternative for Player D and pushes it to accept a higher demand from Player $\mathrm{C}$ to avoid the costly war.

The intervention changes the size of the optimal demand, and the change in the optimal demand affects the probability of war.

Proposition 8 When there is a chance of a third party intervention that targets Player D's costs, the probability of war decreases.

The intervention that targets Player D's costs makes high proposals acceptable for Player D, as a result of which the probability of war decreases. This is an interesting result, as it states that above mentioned type of coercive intervention may actually reduce the risk of war.

\subsection{Intervention that changes the balance of power in favor of Defender}

This subsection considers a Player $\mathrm{R}$ which considers an intervention in the case of war aiming to increase the probability that Player $\mathrm{D}$ will win the war. The probability of winning the war is $p$ for Player $\mathrm{C}$ and $1-p$ for Player $\mathrm{D}$, as a result of intervention there is a shift in this distribution of power by $\lambda$, so that it becomes $p-\lambda$ for Player $\mathrm{C}$ and $1-p+\lambda$ for Player $\mathrm{D}$.

When parties fail to negotiate and go to war, Player $\mathrm{R}$ has a choice intervening through shifting the balance of power in favor of Player D or not intervening at all. This choice depends on its net utility from intervention. Assume Player D gets net utility of 0 if it does not intervene and net utility of $U_{R}-C_{R}$ from intervention. $C_{R} \in[0,1]$ is the intervention cost for Player $\mathrm{R}$. The Player $\mathrm{R}$ intervenes only if its net utility from intervention is higher than its net utility from staying aside, when $U_{R}-C_{R} \geq 0$. 


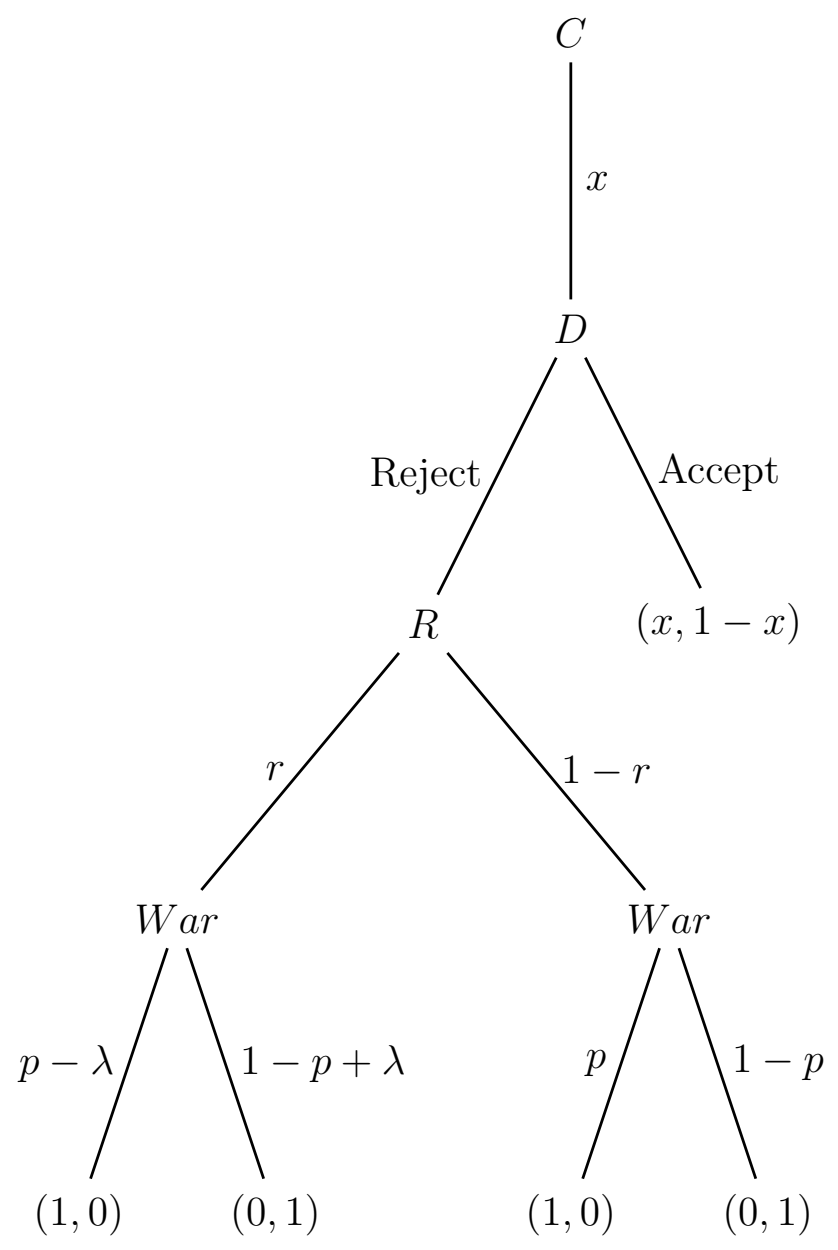

Figure 6: Intervention that shifts the balance of power in favor of Defender. 


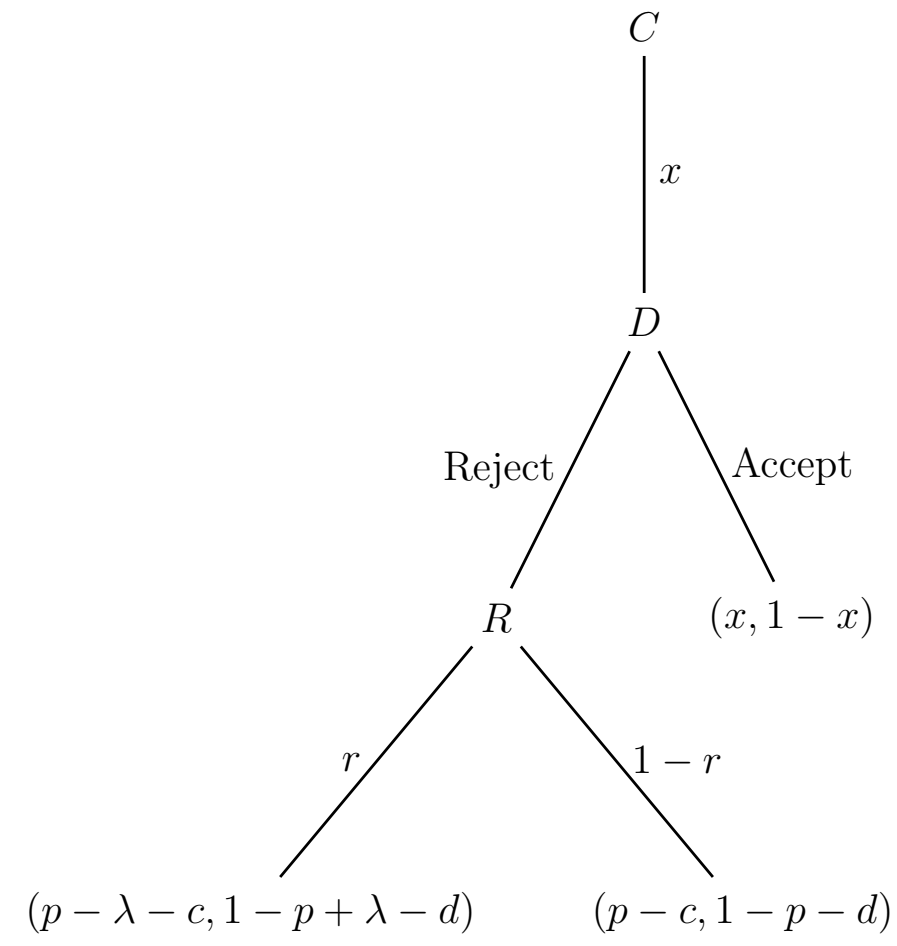

Figure 7: Intervention that shifts the balance of power in favor of Defender, Reduced Game. 
Assume that the costs of intervention is common knowledge and the information about the secured level of utility from intervention is incomplete. Its distribution, which is uniform in $[0,1]$, is common knowledge.

Suppose that the cost of intervention is $C_{R}=1-r$, where $r \in[0,1]$, so that the distance between point $C_{R}$ and 1 is $r$.

The probability that Player $\mathrm{R}$ does not intervene is $\operatorname{Prob}\left(U_{R}-C_{R} \leq 0\right)=$ $\operatorname{Prob}\left(U_{R} \leq 1-r\right)=1-r$. And the probability of intervention is $\operatorname{Prob}\left(U_{R}-U_{C} \geq\right.$ $0)=\operatorname{Prob}\left(U_{R} \geq 1-r\right)=r$.

Thus, players do not know the utility that Player $\mathrm{R}$ gets from intervention, but knowing the distribution of utility level, they distinguish two types of Player R. First type is the one whose utility is greater than costs of intervention and it does intervene, a motivated Player $R$. The second type Player $R$ gets negative net utility from intervention and it chooses not to intervene in case of war, an unmotivated Player $\mathrm{R}$. Two main parties play with these two types of outside players. The probability that they will face a motivated player is $r$ and the probability that it is a unmotivated player is $1-r$.

In this framework Player C's expected payoff for war is:

$$
r(p-\lambda-c)+(1-r)(1-p)=p-\lambda r-c
$$

Player D's expected payoff for war is:

$$
r(1-p+\lambda-d)+(1-r)(1-p-d)=1-p+r \lambda-d
$$

The probability of war as a function of Player C's proposal is:

$$
\pi(x)=\operatorname{Prob}(1-x \leq 1-p+r \lambda-d)=\frac{x-p+r \lambda-\mu+e}{2 e}
$$

The Player $\mathrm{C}$ maximizes its expected utility from war and peace:

$$
U(x)=\pi(x) u(p-\lambda+c)+(1-\pi(x)) u(x) .
$$

It is worth to investigate how the optimal offer changes when there is a chance of intervention compared with the case when Player $\mathrm{C}$ is sure that there will not be any intervention during the war. The possible intervention increases the probability of winning for Player D and makes it more likely to reject the offer and go to war, while Player $\mathrm{C}$ has lower chance of winning the war and in order to avoid war it will decrease its demand making it more acceptable for Player D.

Proposition 9 The optimal offer of Player $C$ decreases when there is a chance of intervention by a third party that changes the probability of winning the war in favor of Player D. 
This result follows from the Proposition 5, which shows the lower the probability of Player $\mathrm{C}$ winning the war the lower is the demand that Player C makes. Since the intervention by Player $\mathrm{R}$ decreases the probability of winning for Player $\mathrm{C}$, it also decreases the optimal demand of Player $\mathrm{C}$.

The following proposition shows how possible intervention shifting the balance of power also affects the probability of war.

Proposition 10 A possible intervention that shifts the balance of power in favor of Player D decreases the probability of war if it is high enough $\left(\pi \geq \frac{3}{4}-\frac{\mu+c}{4 e}\right)$ and $u^{\prime \prime}$ is non-decreasing.

This result follows from the Proposition 6. The proposition states that an intervention shifting the balance of power may reduce high probability of war.

\subsection{The joint effect of a two-sided intervention}

This subsection considers the case when the intervention by Player T and Player $\mathrm{R}$ happens simultaneously. Player T targets Player D's costs and Player R shifts the balance of power in favor of Player D.

If the Player D rejects Player C's proposal, parties go to war, where Player T and Player $\mathrm{R}$ take a role. Player $\mathrm{T}$ has two actions, either to intervene by increasing Player D's costs or not to intervene at all. Regardless the actions of Player T, Player $\mathrm{R}$ either chooses to intervene by decreasing the probability of winning for Player $\mathrm{C}$ or not to intervene. Their decision depends on the net utilities that they get from intervention. The same assumptions about the available information of their net utilities is kept here and, additionally, it is assumed that the utility and costs that one player gets is independent of the actions of the other player, so that the decision about intervention is made independently from each other.

In case of failed negotiations Player $\mathrm{C}$ and Player $\mathrm{D}$ will face with motivated or unmotivated Player T and motivated or unmotivated Player R.

Player D's expected payoff of war is:

$t[r(1-p+\lambda-d-\delta)+(1-r)(1-p-d-\delta)]+(1-t)[r(1-p+\lambda-d)+(1-r)(1-p-d)]=1-p+r \lambda-d-r \delta$.

Where $r \lambda$ captures the level of intervention of Player $\mathrm{R}$ and $t \delta$ is the level of intervention of Player $\mathrm{T}$.

Player C proposes $x$ which is acceptable for Player D, this is the case if

$$
U(1-x) \geq U(1-p+r \lambda-d-r \delta),
$$




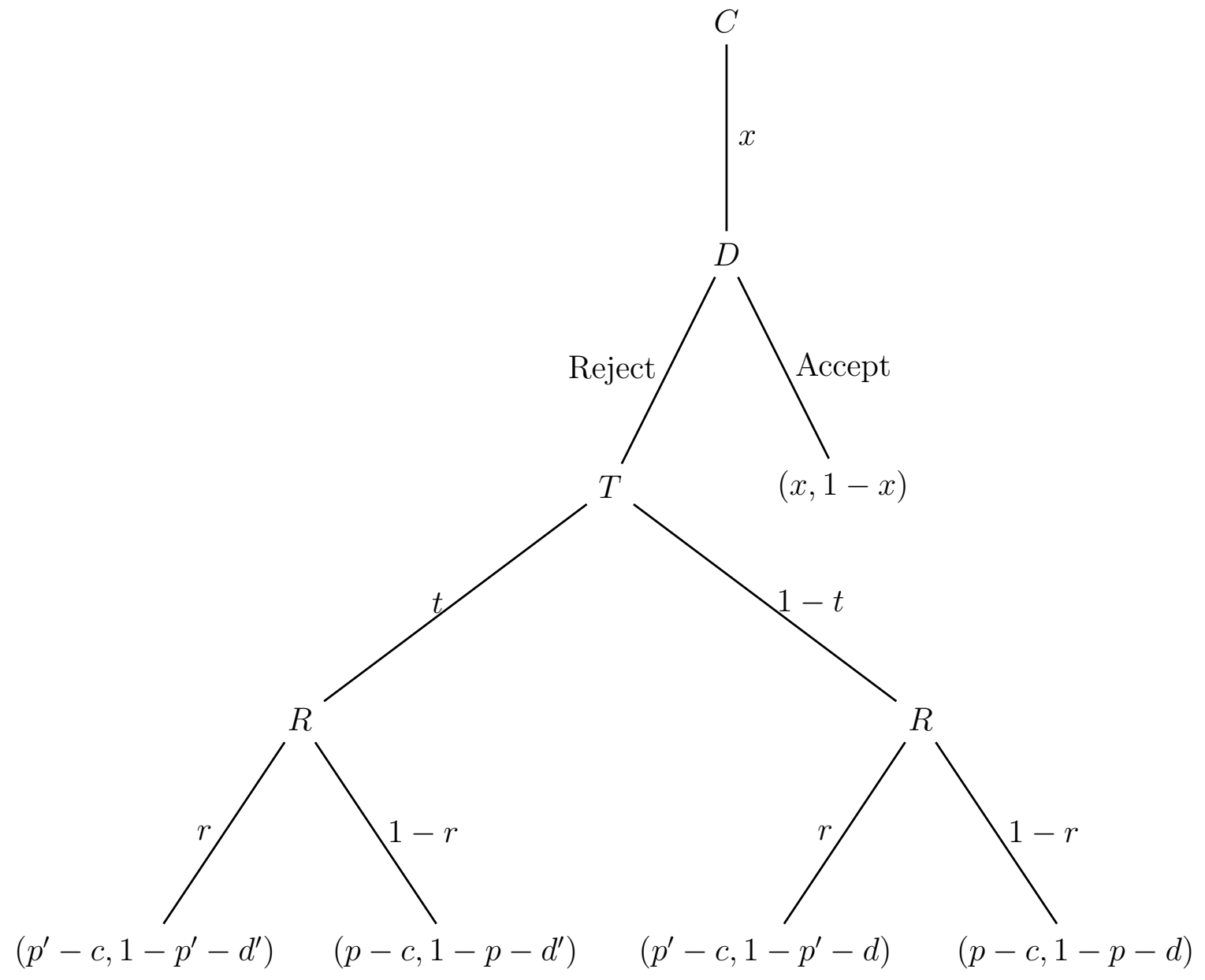

Figure 8: Simultaneous interventions by Players $\mathrm{R}$ and $\mathrm{T}$, where $p^{\prime}=p-\lambda, d^{\prime}=d+\delta$. 
from which follows $x \leq p-r \lambda+d+r \delta$.

However, the proposed $x$ may actually be greater from the marginal level, as a result parties will go to war. The probability of war is:

$$
\pi(x)=\operatorname{Prob}(x>p-r \lambda+d+r \delta)=\frac{x-p+r \lambda-\mu-t \delta+e}{2 e}
$$

While proposing $x$, Player $\mathrm{C}$ maximizes its expected utility taking into account the probability of war. When Player D accepts the offer, Player $\mathrm{C}$ gets $x$ and its utility is $u(x)$, when parties go to war, Player $\mathrm{C}$ has the following expected payoff from war:

$$
t[r(p-\lambda-c)+(1-r)(p-c)]+(1-t)[r(p-\lambda-c)+(1-r)(p-c)]=p-r \lambda-c
$$

So that it will get utility of $u(p-r \lambda-c)$ by probability of $\pi(x)$. Player C's expected utility is:

$$
U(x)=(1-\pi(x)) u(x)+\pi(x) u(p-r \lambda-c)
$$

The optimal offer of Player $\mathrm{C}$ that maximizes its expected payoff is denoted by $x^{*}$. At that point the differential of the expected utility with respect to $x$ should be equal to zero.

$$
\frac{\partial \pi}{\partial x}\left(x^{*}\right)\left(u\left(x^{*}\right)-u(p-r \lambda-c)\right)=\left(1-\pi\left(x^{*}\right)\right) u^{\prime}\left(x^{*}\right) .
$$

We note that the RHS of above equation is nonnegative. Since

$$
\frac{\partial \pi}{\partial x}\left(x^{*}\right)=\frac{1}{2 e} \geq 0
$$

it follows that

$$
u\left(x^{*}\right)-u(p-r \lambda-c) \geq 0 .
$$

As the function $u$ is non-decreasing:

$$
x^{*} \geq p-r \lambda-c .
$$

So, $[p-r \lambda-c, 1]$ is the range from where Player $\mathrm{C}$ will make its proposal. Note that this range is larger than it is in the case when there are no possibilities of interventions (see the inequality 3 ).

The following proposition shows how Player C's optimal demand changes due to the possibility of those two simultaneous interventions.

Proposition 11 As a result of two two-side possible interventions Player $C$ decreases its demand from Player $D$ if the level of intervention of Player $R$ is higher than the one of Player T. Even in case when the intervention levels are balanced, the optimal demand of Player $C$ is lower than when there is no chance of intervention. 


\section{Conclusion}

The paper models a dispute between two states over a territory that is controlled by one state (Defender) and demanded by the other (Challenger). The two states start by bargaining and, if the negotiations fail, they go to war. The model is applied to the case of one of the most acute conflicts in modern times, the Nagorno-Karabakh conflict.

The constructed model allows to investigate the probability of war depending on several factors. Analysis of the model under the assumption of perfect information show that there is no risk of war when disputants are perfectly informed about each other's costs, the distribution of power, and the gains associated with different outcomes. In relation to the Nagorno-Karabakh conflict the model implies that if Armenia and Azerbaijan credibly disclose information about themselves, they can resolve the dispute through peace talks and avoid war. However, states are rarely informed about each other completely. Therefore the assumption about perfect information is relaxed and uncertainty over the costs for fighting is incorporated into the model.

Comparative statics analyses show that an increase in the level of uncertainty leads to an increase in the demand proposed by Challenger to Defender. In the instance of the Nagorno-Karabakh conflict, this implies that Armenia by disclosing private information about its fighting costs can get lower demand from Azerbaijan. Comparative analysis of the costs for fighting shows that the higher the costs of war for Challenger, the lower its demand is from Defender, and the lower the probability of war is. In the case of the Nagorno-Karabakh conflict, Challenger is Azerbaijan; one of the fastest growing economies in the world, which substantially increases its military expenditures; this may indicate that Azerbaijan is becoming stronger over time and the costs of war for that country are decreasing. According to the propositions of the model, this will increase the demand Azerbaijan makes from Armenia, however, if Armenia's willingness of making concessions stay unaltered, the probability of war will be rising.

The model also analyzes the effect of outside interventions on the probability of war and final outcome. First, a form of intervention which targets Defender's costs is investigated, revealing that this form of possible intervention increases Challenger's optimal demand and decreases the probability of war. In the case of the NagornoKarabakh conflict it implies that Turkey, by closing its border with Armenia, encourages Azerbaijan to make a higher demand and makes Armenia more likely to accept that higher demand, since Armenia, due to the intervention by Turkey, faces higher costs of war. As a result of such an intervention by Turkey the probability of 
war decreases.

Second, a form of intervention is investigated that shifts the balance of power in favor of the Defender. This form of possible intervention decreases Challenger's optimal demand and decreases the probability of war if it is high. This implies that a possible intervention by Russia in Nagorno-Karabakh conflict in favor of Armenia induces Azerbaijan to take a less assertive role in the process of bargaining, and this makes the war a less likely outcome.

The investigation of the joint effect of both forms of interventions shows that the overall effect depends on a comparison of the levels of interventions. For example, if the level of Russian intervention proportionally exceeds the level of Turkish intervention, Azerbaijan decreases its demand.

The model introduced in this paper is a basic model and generalizations can be made. For example, the model can be generalized by adopting Rubinstein (1982)'s alternating-offer, infinite-horizon game, where disputants alternate proposing offers each other. Whenever a player is considering whether to accept or reject the offer to make a counteroffer, it also has a third option of imposing a settlement, that is, go to war. The game ends when the players agree on a division or go to war. Another modification of the model is based on the ways of incorporating uncertainty into the model. Different ways and variables over which an uncertainty is incorporated into the model define different models which may or may not imply the same results. The uncertainty is introduced over the costs for fighting in this model. Alternatively, uncertainty could be incorporated over the distribution of power. The analysis of the effects of intervention in the model is limited to two forms of coercive interventions with each state being subject to only one form of intervention. In reality states may be subject to more than one form of interventions, even though one form of intervention may dominate the other. Thus, the model can be generalized using a more complex approach to the options of outside intervention. The model can also consider incorporating strategic interventions and deriving Perfect Bayesian equilibria. Another interesting extension of the model is the possibility for the Defender to send signals about its cost of fighting with purpose of lowering the demand from Challanger. This will define a signaling game, which is especially interesting for the case of the Nagorno-Karabakh conflict. 


\section{References}

Fearon, J. D. (1995). Rationalist explanations for war, International Organization 49(3): 379-414.

Powell, R. (1996). Bargaining in the shadow of power, Games and Economic Behavior 15: 255-289.

Powell, R. (2004). Bargaining and learning while fighting, American Journal of Political Science 48(2): 344-361.

Rauchhaus, R. (2005). Third parties, coercive intervention and conflict management, annual meeting of the American Political Science Association. Washington, DC, September, pp. 1-5.

Rubinstein, A. (1982). Perfect equilibrium in a bargaining model, Econometrica: Journal of the Econometric Society pp. 97-109.

Siqueira, K. (2003). Conflict and third-party intervention, Defence and Peace Economics 14(4): $389-400$. 


\section{A Appendix}

\section{A.1 Proof of Proposition 2}

We need to show that $\frac{\partial x^{*}}{\partial e} \geq 0$. Recall that the probability of war attached to the demand (or offer) $x$, depends also on the level of uncertainly, $e$ and, by (1), one has

$$
\pi=\pi(x, e)=\frac{x-p-\mu+e}{2 e} .
$$

Hence $\frac{\partial \pi}{\partial x}(x, e)=\frac{1}{2 e}$, and the First Order Necessary Condition (2) becomes

$$
\frac{1}{2 e}\left(u\left(x^{*}(e)\right)-u(p-c)\right)=\left(1-\pi\left(x^{*}(e), e\right)\right) u^{\prime}\left(x^{*}(e)\right) .
$$

Differentiating the above equality w.r.t. the level of uncertainly, $e$, gives

$$
-\frac{1}{2 e^{2}}\left(u\left(x^{*}\right)-u(p-c)\right)+\frac{1}{2 e} u^{\prime}\left(x^{*}\right) \frac{\partial x^{*}}{\partial e}=-\frac{\mathrm{d} \pi}{\mathrm{d} e}\left(x^{*}, e\right) u^{\prime}\left(x^{*}\right)+\left(1-\pi\left(x^{*}, e\right)\right) u^{\prime \prime}\left(x^{*}\right) \frac{\partial x^{*}}{\partial e} .
$$

Moreover, from Equation (1), one easily gets

$$
\begin{aligned}
\frac{\mathrm{d} \pi}{\mathrm{d} e}\left(x^{*}, e\right) & =\frac{\partial \pi}{\partial x} \frac{\partial x^{*}}{\partial e}+\frac{\partial \pi}{\partial e} \\
& =\frac{1}{2 e} \frac{\partial x^{*}}{\partial e}+\frac{p+\mu-x^{*}}{2 e^{2}} .
\end{aligned}
$$

Substituting the last expression (6) in Equation (5) and rearranging the terms, we obtain

$$
\frac{\partial x^{*}}{\partial e}\left(\frac{1}{e} u^{\prime}\left(x^{*}\right)-\left(1-\pi\left(x^{*}\right)\right) u^{\prime \prime}\left(x^{*}\right)\right)=\frac{1}{2 e^{2}}\left(u\left(x^{*}\right)-u(p-c)-\left(p+\mu-x^{*}\right) u^{\prime}\left(x^{*}\right)\right) .
$$

Note that the sign of the coefficient of $\frac{\partial x^{*}}{\partial e}$ in the LHS of the above Equation is unambiguously positive. This follows from the assumption of risk averse utility function. So the sign of the $\frac{\partial x^{*}}{\partial e}$ is determined by the sign of the RHS of Equation (7). Note that

$$
\begin{aligned}
2 e^{2} \times \mathrm{RHS} & =u\left(x^{*}\right)-u(p-c)-\left(p+\mu-x^{*}\right) u^{\prime}\left(x^{*}\right) \\
& =\left(u\left(x^{*}\right)-u(p-c)\right)\left(1-\frac{\left(p+\mu-x^{*}\right) u^{\prime}\left(x^{*}\right)}{u\left(x^{*}\right)-u(p-c)}\right) \\
& =\left(u\left(x^{*}\right)-u(p-c)\right)\left(1-\left(p+\mu-x^{*}\right) \frac{\frac{\partial \pi}{\partial x}}{1-\pi\left(x^{*}\right)}\right) \text { by }(2)
\end{aligned}
$$




$$
\begin{aligned}
& =\frac{u\left(x^{*}\right)-u(p-c)}{1-\pi\left(x^{*}\right)}\left(1-\pi\left(x^{*}\right)-\left(p+\mu-x^{*}\right) \frac{\partial \pi}{\partial x}\right) \\
& =\frac{u\left(x^{*}\right)-u(p-c)}{1-\pi\left(x^{*}\right)}\left(1-\frac{x^{*}-p-\mu+e}{2 e}-\left(p+\mu-x^{*}\right) \frac{1}{2 e}\right) \\
& =\frac{1}{2} \frac{u\left(x^{*}\right)-u(p-c)}{1-\pi\left(x^{*}\right)} \\
& \geq 0
\end{aligned}
$$

Note that $u\left(x^{*}\right)-u(p-c) \geq 0$ is nothing but Inequality (3). Therefore,

$$
\frac{\partial x^{*}}{\partial e} \geq 0
$$

This shows that C's optimal demand is a non-decreasing function of the level of uncertainly, $e$, and ends the proof of Proposition 2.

\section{A.2 Proof of Proposition 3}

In order to identify the effect of the level of uncertainly on the probability of war, we differentiate the latter with respect to $e$. From (6), we have

$$
\frac{\mathrm{d} \pi}{\mathrm{d} e}\left(x^{*}, e\right)=\frac{1}{2 e} \frac{\partial x^{*}}{\partial e}+\frac{p+\mu-x^{*}}{2 e^{2}} .
$$

Note that $\frac{1}{2 e} \geq 0$ and, by Proposition $2, \frac{\partial x^{*}}{\partial e} \geq 0$. The sign of $\frac{\mathrm{d} \pi}{\mathrm{de}}$ depends on the sign of $p+\mu-x^{*}$ which in turn depends on the magnitude of probability of war. Indeed,

$$
p+\mu-x^{*}=p+\mu-\left(2 e \pi\left(x^{*}\right)+p+\mu-e\right)=e\left(1-2 \pi\left(x^{*}\right)\right) .
$$

Hence, if $\pi\left(x^{*}\right)<\frac{1}{2}$, then $\frac{\mathrm{d} \pi}{\mathrm{de}}>0$.

\section{A.3 Proof of Proposition 4}

Differentiating Equation (2) with respect to $c$ gives:

$$
\frac{\partial \pi}{\partial x}\left(x^{*}\right)\left(u^{\prime}\left(x^{*}\right) \frac{\partial x^{*}}{\partial c}+u^{\prime}(p-c)\right)=-\left(\frac{\partial \pi}{\partial x} \frac{\partial x^{*}}{\partial c}\right) u^{\prime}\left(x^{*}\right)+\left(1-\pi\left(x^{*}\right)\right) u^{\prime \prime}\left(x^{*}\right) \frac{\partial x^{*}}{\partial c}
$$

Plugging $\frac{\partial \pi}{\partial x}=\frac{1}{2 e}$ (from (1)) into the previous equality and rearranging the terms results in:

$$
\frac{\partial x^{*}}{\partial c}=\frac{\frac{1}{2 e} u^{\prime}(p-c)}{\left(1-\pi\left(x^{*}\right)\right) u^{\prime \prime}\left(x^{*}\right)-\frac{1}{e} u^{\prime}\left(x^{*}\right)} .
$$


From the assumption of risk averse utility function, it follows that the numerator of the RHS of Equation (9) is positive and its denominator is negative. Hence

$$
\frac{\partial x^{*}}{\partial c} \leq 0
$$

Now we show that $\frac{\mathrm{d} \pi}{\mathrm{d} c} \leq 0$. We have

$$
\frac{\mathrm{d} \pi}{\mathrm{d} c}=\frac{\partial \pi}{\partial x} \frac{\partial x^{*}}{\partial c} .
$$

As, $\frac{\partial x^{*}}{\partial c} \leq 0$ (by $(10)$ ), and $\frac{\partial \pi}{\partial x}=\frac{1}{2 e} \geq 0$ (by (1)), it follows that $\frac{\mathrm{d} \pi}{\mathrm{d} c} \leq 0$.

\section{A.4 Proof of Proposition 5}

We need to show $\frac{\partial x^{*}}{\partial p}>0$. Differentiating Equation (2) with respect to $p$, gives:

$\frac{\partial \pi}{\partial x}\left(x^{*}\right)\left(u^{\prime}\left(x^{*}\right) \frac{\partial x^{*}}{\partial p}-u^{\prime}(p-c)\right)=-\left(\frac{\partial \pi}{\partial x} \frac{\partial x^{*}}{\partial p}+\frac{\partial \pi}{\partial p}\right) u^{\prime}\left(x^{*}\right)+\left(1-\pi\left(x^{*}, p\right)\right) u^{\prime \prime}\left(x^{*}\right) \frac{\partial x^{*}}{\partial p}$

Rearranging the terms while taking into account the fact that $\frac{\partial \pi}{\partial x}=\frac{1}{2 e}$ and $\frac{\partial \pi}{\partial p}=-\frac{1}{2 e}$ gives,

$$
\frac{\partial x^{*}}{\partial p}=\frac{1}{2 e} \frac{u^{\prime}(p-c)+u^{\prime}\left(x^{*}\right)}{\frac{u^{\prime}\left(x^{*}\right)}{e}-\left(1-\pi\left(x^{*}\right)\right) u^{\prime \prime}\left(x^{*}\right)}
$$

Both the numerator and denominator of the RHS of Equation (11) are positive because of the assumption of the risk averse utility function. It follows that $\frac{\partial x^{*}}{\partial p} \geq 0$.

\section{A.5 Proof of Proposition 6}

We need to prove that $\frac{\mathrm{d} \pi}{\mathrm{d} p}>0$. We have

$$
\frac{\mathrm{d} \pi}{\mathrm{d} p}=\frac{\partial \pi}{\partial x} \frac{\partial x^{*}}{\partial p}+\frac{\partial \pi}{\partial p}=\frac{1}{2 e} \frac{\partial x^{*}}{\partial p}-\frac{1}{2 e}=\frac{1}{2 e}\left(\frac{\partial x^{*}}{\partial p}-1\right) .
$$

It follows that $\operatorname{sign}\left(\frac{\mathrm{d} \pi}{\mathrm{d} p}\right)=\operatorname{sign}\left(\frac{\partial x^{*}}{\partial p}-1\right)$. From Equation (11) we have

$$
\frac{\partial x^{*}}{\partial p}=\frac{u^{\prime}(p-c)+u^{\prime}\left(x^{*}\right)}{2 u^{\prime}\left(x^{*}\right)-2 e\left(1-\pi\left(x^{*}\right)\right) u^{\prime \prime}\left(x^{*}\right)} .
$$

Note that determining the sign of $\left(\frac{\partial x^{*}}{\partial p}-1\right)$ is the same as comparing the numerator and denominator of the RHS of the above equality. Denote by $\Delta$ the difference 
between the numerator and denominator of the RHS of the above equality. We claim that $\Delta>0$. Indeed,

$$
\begin{aligned}
\Delta & =u^{\prime}(p-c)+u^{\prime}\left(x^{*}\right)-2 u^{\prime}\left(x^{*}\right)+2 e\left(1-\pi\left(x^{*}\right)\right) u^{\prime \prime}\left(x^{*}\right) \\
& =u^{\prime}(p-c)-u^{\prime}\left(x^{*}\right)+2 e\left(1-\pi\left(x^{*}\right)\right) u^{\prime \prime}\left(x^{*}\right) \\
& =-\left(x^{*}-p+c\right) u^{\prime \prime}(\gamma)+2 e\left(1-\pi\left(x^{*}\right)\right) u^{\prime \prime}\left(x^{*}\right)
\end{aligned}
$$

where $\gamma \in\left(p-c, x^{*}\right)$ (recall that by (3), we have $p-c \leq x^{*}$ ). By assumption, $x^{*} \geq p+\frac{\mu+e-c}{2}$. Recalling that $\pi\left(x^{*}\right)=\frac{x^{*}-p-\mu+e}{2 e}$ (from $(1)$ ), one can easily check that $x^{*}-p+c \geq 2 e\left(1-\pi\left(x^{*}\right)\right)$. Hence

$$
\begin{aligned}
\Delta & \geq 2 e\left(1-\pi\left(x^{*}\right)\right)\left(u^{\prime \prime}\left(x^{*}\right)-u^{\prime \prime}(\gamma)\right) \\
& \geq 0 .
\end{aligned}
$$

Where, for the last inequality, we use the fact that $u^{\prime \prime}$ is nondecreasing and $\gamma<x^{*}$. This ends the proof of the claim. Therefore $\frac{\mathrm{d} \pi}{\mathrm{d} p}>0$.

\section{A.6 Proof of Proposition 7}

Let's denote Challenger's optimal demand by $x_{0}$ when there is no chance of intervention and by $x_{1}$ when there is a chance of intervention. We need to prove that $x_{1} \geq x_{0}$. Denote the probability of war without (respectively, with) intervention by $\pi_{0}$ (respectively, $\pi_{1}$ ). Then

$$
\begin{aligned}
\pi_{0}(x) & =\frac{x-p-\mu+e}{2 e} \\
\pi_{1}(x) & =\frac{x-p-\mu-t \delta+e}{2 e} .
\end{aligned}
$$

It is easy to see that

$$
\pi_{1}(x)=\pi_{0}(x)-\frac{t \delta}{2 e}
$$

Whether there is chance of intervention or not, Player $\mathrm{C}$ is maximizing her expected utility (for $i=1,2$ )

$$
U_{c}(x)=u(p-c)+\left(1-\pi_{i}(x)\right)(u(x)-u(p-c)) .
$$

Hence Player C's optimal demand, $x_{i}$ for $i \in\{1,2\}$, satisfies the following first order necessary condition

$$
\frac{\partial \pi_{i}}{\partial x}\left(x_{i}\right)\left(u\left(x_{i}\right)-u(p-c)\right)-\left(1-\pi_{i}\right) u^{\prime}\left(x_{i}\right)=0 .
$$


Define the following function:

$$
F(x)=\frac{\partial \pi_{0}}{\partial x}(x)(u(x)-u(p-c))-\left(1-\pi_{0}(x)\right) u^{\prime}(x) .
$$

It follows from Equation (14) that $F\left(x_{0}\right)=0$. Rewriting Equation (14) for $i=1$ and taking into account the equalities $\pi_{1}(x)=\pi_{0}(x)-\frac{t \delta}{2 e}$ and $\frac{\partial \pi_{0}}{\partial x}=\frac{\partial \pi_{1}}{\partial x}=\frac{1}{2 e}$ gives:

$$
\frac{\partial \pi_{0}}{\partial x}\left(x_{1}\right)\left(u\left(x_{1}\right)-u(p-c)\right)-\left(1-\pi_{0}\left(x_{1}\right)+\frac{t \delta}{2 e}\right) u^{\prime}\left(x_{1}\right)=0 .
$$

Hence $F\left(x_{1}\right)=\frac{t \delta}{2 e} u^{\prime}\left(x_{1}\right)$, and one easily concludes that $F\left(x_{1}\right) \geq 0=F\left(x_{0}\right)$. Now we claim that $F^{\prime}(x) \geq 0$. Indeed, since $\frac{\partial \pi_{0}}{\partial x}=\frac{1}{2 e}$, one has

$$
F^{\prime}(x)=\frac{1}{e} u^{\prime}(x)-\left(1-\pi_{0}(x)\right) u^{\prime \prime}(x) \geq 0
$$

This ends the proof of the claim. Therefore, $F(x)$ is a non-decreasing function and from $F\left(x_{1}\right) \geq F\left(x_{0}\right)$, it follows that $x_{1} \geq x_{0}$.

\section{A.7 Proof of Proposition 8}

We need to show that $\pi_{1}\left(x_{1}\right) \leq \pi_{0}\left(x_{0}\right)$. Subtracting Equation (12) from Equation (13), we get:

$$
\pi_{1}\left(x_{1}\right)-\pi_{0}\left(x_{0}\right)=\frac{x_{1}-x_{0}-t \delta}{2 e} .
$$

So, it is enough to show that

$$
x_{1}-x_{0}-t \delta \leq 0 .
$$

Using the function $F$ defined by (15), we know that $F\left(x_{1}\right)-F\left(x_{0}\right)=\frac{t \delta}{2 e} u^{\prime}\left(x_{1}\right)$. On the other hand, one can write

$$
F\left(x_{1}\right)-F\left(x_{0}\right)=F^{\prime}(\alpha)\left(x_{1}-x_{0}\right)
$$

for some $\alpha \in\left(x_{0}, x_{1}\right)$. That is $\frac{t \delta}{2 e} u^{\prime}\left(x_{1}\right)=F^{\prime}(\alpha)\left(x_{1}-x_{0}\right)$. Rearranging the terms, we get:

$$
\begin{aligned}
\frac{t \delta}{x_{1}-x_{0}} & =2 e \frac{F^{\prime}(\alpha)}{u^{\prime}\left(x_{1}\right)} \\
& =2 \frac{u^{\prime}(\alpha)}{u^{\prime}\left(x_{1}\right)}-2 e\left(1-\pi_{0}(\alpha)\right) \frac{u^{\prime \prime}(\alpha)}{u^{\prime}\left(x_{1}\right)}
\end{aligned}
$$


Because $\alpha \leq x_{1}$ and $u^{\prime \prime}(x) \leq 0$, one has $u^{\prime}(\alpha) \geq u^{\prime}\left(x_{1}\right)$. Since $u^{\prime}>0$, we conclude that the first term of the RHS of Equation (17) is greater then equal to two. And because the second term is nonnegative, It follows that $\frac{t \delta}{x_{1}-x_{0}} \geq 2 \geq 1$ and

$$
x_{1}-x_{0}-t \delta \leq 0 \text {. }
$$

That is what we wanted to show.

\section{A.8 Proof of Proposition 11}

Let's again denote Challenger's optimal demand made by $x_{0}$ when there is no chance of intervention and $x_{1}$ when there is chance of interventions.

The probability of war without intervention is:

$$
\pi_{0}(x)=\frac{x-p-\mu+e}{2 e}
$$

and the probability of war with interventions is:

$$
\pi_{1}(x)=\frac{x-p+r \lambda-\mu-t \delta+e}{2 e}
$$

It is easy to see that

$$
\pi_{1}(x)=\pi_{0}(x)-\frac{t \delta-r \lambda}{2 e}
$$

Player's C maximizes its expected utility at $x_{1}$.

$$
\frac{\partial \pi_{1}}{\partial x}\left[u\left(x_{1}\right)-u(p-r \lambda-c)\right]-\left(1-\pi_{1}\right) u^{\prime}\left(x_{1}\right)=0
$$

When there is no chance of intervention the derivative of the expected utility at the point $x_{0}$ is zero (Equation (2)).

$$
\frac{\partial \pi_{0}}{\partial x}\left[u\left(x_{0}\right)-u(p-c)\right]-\left(1-\pi_{0}\right) u^{\prime}\left(x_{0}\right)=0
$$

Let's denote by $F$ the following function:

$$
F(x)=\frac{\partial \pi_{0}}{\partial x}\left[u\left(x^{*}\right)-u(p-c)\right]-\left(1-\pi_{0}(x)\right) u^{\prime}\left(x^{*}\right)
$$

From Equation (21) immediately follows that $F\left(x_{0}\right)=0$

Rewriting Equation (20) taken into account 


$$
\begin{aligned}
& \pi_{1}(x)=\pi_{0}(x)-\frac{t \delta-r \lambda}{2 e} \text { and that } \frac{\partial \pi_{0}}{\partial x}=\frac{\partial \pi_{1}}{\partial x}=\frac{1}{2 e} \text { gives: } \\
& \frac{1}{2 e}\left[u\left(x_{1}\right)-u(p-r \lambda-c)\right]-\left(1-\pi_{0}\left(x_{1}\right)+\frac{t \delta-r \lambda}{2 e}\right) u^{\prime}\left(x_{1}\right)+\frac{1}{2 e}(u(p-c)-u(p-c))=0
\end{aligned}
$$

Rewriting,

$$
\frac{1}{2 e}\left[u\left(x_{1}\right)-u(p-c)\right]-\left(1-\pi_{0}\left(x_{1}\right)\right) u^{\prime}\left(x_{1}\right)=\frac{1}{2 e}(u(p-r \lambda-c)-u(p-c))+\frac{t \delta-r \lambda}{2 e} u^{\prime}\left(x_{1}\right)
$$

Noting that LHS of above Equation is nothing else than function $F$ at $x_{1}$, gives

$$
F\left(x_{1}\right)=\frac{1}{2 e}(u(p-r \lambda-c)-u(p-c))+\frac{t \delta-r \lambda}{2 e} u^{\prime}\left(x_{1}\right) .
$$

Now consider the following cases:

Case 1: $t \delta=r \lambda$

In this case we have that

$$
F\left(x_{1}\right)=\frac{1}{2 e}(u(p-r \lambda-c)-u(p-c)) \leq 0
$$

as $p-r \lambda-c \leq p-c$ and $u$ is nondecreasing function. In the section 7 it is proved that $F(x)$ is non-decreasing function and as $F\left(x_{1}\right)<F\left(x_{0}\right)$, it follows that $x_{1}<x_{0}$.

Case 2: $t \delta<r \lambda$

It follows that $F\left(x_{1}\right)<0=F\left(x_{0}\right)$. It follows that $x_{1}<x_{0}$.

Case 3: $t \delta>r \lambda$

The result is ambiguous. 